\title{
Antagonists to the Wnt Cascade Exhibit Sex-Specific Expression in Gonads of Sexually Mature Shovelnose Sturgeon
}

\author{
J.J. Amberg R.R. Goforth M.S. Sepúlveda \\ Department of Forestry and Natural Resources, Purdue University, West Lafayette, Ind., USA
}

\section{Key Words}

Fish $\cdot$ dact 1 $\cdot d k k 1 \cdot d m r t 1 \cdot$ foxl2 $\cdot$ Scaphirhynchus

platorynchus $\cdot$ Sex $\cdot$ Sturgeon $\cdot$ Wnt cascade

\begin{abstract}
Little is known regarding molecular mechanisms involved in sex determination and differentiation in sturgeon species. We addressed this knowledge gap by using next generation pyrosequencing technology to provide transcript libraries and species-specific sequences for mature gonads of shovelnose sturgeon, Scaphirhynchus platorynchus. We then mined these libraries to identify gender-specific transcripts and quantified relative transcript abundance using quantitative real-time polymerase chain reaction (qPCR). We detected a limited number of genes known to play a role in sex differentiation in other species. The sequence for $d m r t 1$ was found only in the testes library. The abundance of $d m r t 1$ differed slightly between the sexes, but the melt curve suggests that there may be different isoforms of $d m r t 1$ in ovaries and testes of shovelnose sturgeon. The transcription factor foxl 2 was 5.3-fold greater in ovaries than in testes. Two antagonists to the Wnt cascade, dickkopf-1 (dkk1) and dapper-1 (dact1), were found only in the ovary library. Results
\end{abstract}

\section{KARGER}

E-Mail karger@karger.com

www.karger.com/sxd from qPCR indicated that $d k k 1$ and dact 1 were upregulated 1,819.1- and 207.5-fold, respectively, in ovaries compared with testes. These results suggest that antagonists to the Wnt cascade may play significant roles in sex differentiation and gonadal development in sturgeon and could serve as sex markers in this group of ancient fish.

C) 2013 S. Karger AG, Basel

Twenty-eight of the 31 extant sturgeon species are classified as vulnerable, threatened or endangered, and 17 are classified as critically endangered (World Sturgeon Conservation Society 2010, www.wscs.info). Sturgeon aquaculture production has thus substantially increased for both hatchery propagation and to supply the caviar industry. For example, it was estimated that sturgeon farming in China (of 11 different species/hybrids) increased 50-fold between 1998 and 2002 [Wei et al., 2004]. Despite this increase, the biology of many sturgeon species remains largely unknown. In particular, there is a great need to better understand how sex is determined and how gonads differentiate, and sex-specific markers need to be developed for this sexually monomorphic group of fish. This information is critical for both the de- (c) 2013 S. Karger AG, Base

$1661-5425 / 13 / 0076-0308 \$ 38.00 / 0$
María S. Sepúlveda

Department of Forestry and Natural Resources, Purdue University 195 Marsteller Street

West Lafayette, IN 47907 (USA)

E-Mail mssepulv@purdue.edu 
velopment of monosex populations for efficient caviar production as well as for the restoration of globally declining sturgeon stocks.

Sex determination and sex differentiation are related terms that refer to distinctly different processes. Sex determination is defined as the genetic and/or environmental forces that determine whether an individual will become a male or a female, whereas sex differentiation refers to molecular and cellular processes that make a bipotential gonadal primordium develop into either a testis or an ovary after sex has been determined [Devlin and Nagahama, 2002]. In sturgeons, sex appears to be genetically determined based on a 1 \%: $10^{x}$ ratio, and for some species, there is evidence consistent with female heterogametic genetic sex determination [Keyvanshokooh and Gharaei, 2010]. Sturgeons are also considered gonochorists since intersex is a rare condition only having been reported from polluted habitats [Harshbarger et al., 2000].

Sex determination and differentiation cascades in vertebrates result from complex interplays among a large number of cell types and network of genes, and it occurs during a relatively narrow window of time. Although the sex specificity and timing of expression for some of these genes differs between species, most are well-conserved and exhibit characteristic expression during the period of sex differentiation [Siegfried, 2010]. Recent data from teleost fishes show that several genes involved in the sex differentiation cascade are also well-conserved across families regardless of the sex determination mechanism involved [Alfaqih et al., 2009]. These genes belong to several families, including transcription factors, germ cell proteins, apoptosis regulators, steroidogenic enzymes, receptors, and growth factors. Thus, it has been proposed that an effective mechanism for determining sexes in sturgeon could be through the identification of genes, gene transcripts or protein markers.

Several approaches have been used for profiling/fingerprinting sex-associated molecular markers in sturgeon, including random amplified polymorphic DNA, amplified fragment length polymorphism, inter-simple sequence repeats, pyrosequencing, and proteomics [Hale et al., 2010; Keyvanshokooh and Gharaei, 2010; Yarmohammadi et al., 2011]. However, no sex-specific markers have been reported from this group of fish to date. We therefore utilized next generation sequencing (NGS) technology followed by quantitative real-time polymerase chain reaction (qPCR) on mature gonads of shovelnose sturgeon, Scaphirhynchus platorynchus, to identify gender-specific transcripts and thus address this critical information gap. The NGS platform utilized in these studies, 454 FLX sequencing (Roche Diagnostics, Branford, Conn., USA), provides longer reads than other platforms [Schirmer et al., 2010], making it an ideal transcriptomic approach for the development of sex markers in sturgeons. We report on the discovery of novel gene transcripts that are highly expressed in females and involved in sex determination and differentiation in mammals that have heretofore not been reported from sturgeon species.

\section{Materials and Methods}

\section{Tissue Collection and Preparation}

Six adult reproductively mature female $(711 \pm 52 \mathrm{~mm})$ and 6 male $(723 \pm 44 \mathrm{~mm})$ shovelnose sturgeons were captured from the Wabash River near West Lafayette, Ind., USA, in April 2008. Fish were transported live to the Indiana Animal Disease Diagnostic Laboratory at Purdue University (West Lafayette, Ind., USA) where they were measured for fork length $(\mathrm{mm})$, weighed $(\mathrm{kg})$ and then euthanized with a lethal dose of FINQUEL MS-222 (Argent Chemical Laboratories, Inc., Redmond, Wash., USA). Sex of each fish was determined at the time of dissection and later corroborated based on histology (H\&E staining as described in Amberg et al. [2010]). Ovaries contained mature black eggs and testes sperm as described in Amberg et al. [2010]. A small portion of each individual's gonad was collected, flash-frozen and stored at $-80^{\circ} \mathrm{C}$ until further processing. All fishes were handled and treated according to the guidelines of the Purdue University's Animal Care and Use Committee (PACUC Protocol 09-040).

Gonad samples $(\approx 100 \mu \mathrm{g})$ were individually placed into $1 \mathrm{ml}$ TRIzol $^{\circledR}$ (Invitrogen, Carlsbad, Calif., USA) and thoroughly homogenized using a Tissue Tearor ${ }^{\mathrm{TM}}$ Homogenizer (BioSpec Products, Inc., Bartlesville, Okla., USA). Total RNA was extracted according to the manufacturer's instructions and then spectrophotometrically quantified using a Nanodrop 1000 (Thermo Fisher Scientific, Waltham, Mass., USA). All RNA samples were then diluted to equal concentrations (i.e. $1 \mu \mathrm{g} / \mu \mathrm{l}$ ).

Libraries

Total RNA ( $>10 \mu \mathrm{g})$ from one ovary and testis was provided to the Purdue Genomic Core (PGC). Tissues from a single fish of each sex were used to create the library since we expected that genome duplication would have made assembly much more difficult. Libraries were not normalized since it has been reported that normalization of libraries does not significantly increase the rate of discovery of new transcripts for libraries with $>4,000$ sequences [Hale et al., 2009]. PGC isolated polyA+ RNA from total RNA from each gonad. This process minimizes the amount of ribosomal RNAs while maximizing the abundance of gene transcripts and the likelihood of discovering novel gene products (Phillip San Miguel, PGC, pers. commun., 2010). Random primed cDNA libraries were created and then sequenced on a Roche GS-FLX (454) sequencer using Titanium chemistry. Libraries were sequenced on the same plate and separated using 'multiplex identifier' barcodes. Upon sequencing completion, PGC provides a web page containing assembled expressed sequence tag sequences and first pass se- 
Table 1. Sets of primers used to quantify transcript abundance by quantitative PCR of targeted genes

\begin{tabular}{|c|c|c|c|}
\hline Gene & Accession No. & Primer & Sequence $\left(5^{\prime}-3^{\prime}\right)$ \\
\hline \multicolumn{4}{|l|}{ Reference genes* } \\
\hline \multirow{2}{*}{ Ribosomal protein S18 (rps18) } & & sense & AAACGGCTACCACATCCAAG \\
\hline & & antisense & CCTCCAATGGATCCTCGTTA \\
\hline \multirow[t]{2}{*}{ Ribosomal protein L22 (rpl22) } & & sense & CAGGAGCGGATCAAGGTAAA \\
\hline & & antisense & GGAAGTAGCGCAGTTCGTAG \\
\hline \multirow[t]{2}{*}{$\beta$-Actin $(a c t b)$} & & sense & TTGCCATCCAGGCTGTGCT \\
\hline & & antisense & TCTCGGCTGTGGTGGTGAA \\
\hline \multirow[t]{2}{*}{ Elongation factor 1-a (efla) } & & sense & CAAGGGCTCCTTCAAGTACG \\
\hline & & antisense & TGTCCAGGGGCATCAATAAT \\
\hline \multicolumn{4}{|l|}{ Target genes } \\
\hline \multirow{5}{*}{$\begin{array}{l}\text { Hypoxia-inducible factor } 1-a \\
\text { (hif1a) } \\
\text { Doublesex and mab-3-related } \\
\text { transcription factor } 1 \text { (dmrt1) }\end{array}$} & JN882598 & sense & ACCGGAGCATTTACTTCACAAT \\
\hline & & antisense & GATCCAAGGCATCTGAGGATAG \\
\hline & GQ403948 & sense & CCAGTACAGGGCACACAGAA \\
\hline & & antisense & TGCATTTGGTACTGCTGGAA \\
\hline & JN882597 & sense & GGCAGGTGTGGAGTCTTGAT \\
\hline Dickkopf $1(d k k 1)$ & & antisense & TATTCCAGCGCTGTGACTGTG \\
\hline \multirow[t]{2}{*}{ Forkhead box L2 (foxl2) } & GQ403949 & sense & TGGGGAAAGGAAGGGTAACT \\
\hline & & antisense & AAGGGAGAGAAGGGGAAAGA \\
\hline \multirow[t]{2}{*}{ Dapperhomolog 1 (dact1) } & JN882596 & sense & TAGGCTTGATTCACTGTCTCCA \\
\hline & & antisense & GCATACATTGGTAGCGACTCTG \\
\hline
\end{tabular}

* Reference primers have been previously published for use with shovelnose sturgeon [Amberg et al., 2010].

quence informatics, including blast searches and blast2GO annotation as well as comparisons between samples as needed. Contigs (gene transcripts) were aligned from individual reads using Newbler 2.5 [Kumar and Blaxter, 2010].

Unique sequences were identified by comparing the sequences of the male libraries with the sequences from the female libraries using BlastN. Unique contigs, isotigs and singletons were then annotated using BlastX and assigned gene ontogeny terms (GO terms) using Blast2Go, and significant GO was determined with an e value $\leq 1 \times 10^{-5}$. GO terms and sequence descriptions were searched to identify genes known to participate in sex determination and differentiation as well as cell differentiation, including transcripts that encode $d m r t 1$, foxl2, sox, vasa, and $a m h$ and the terms Wnt, catenin and spermatogenesis. GOs were then compared between libraries as a percent of the total number of sequences within that library.

\section{Quantitative Real-Time PCR}

RNA from each individual was treated with DNase I (Fermentas Inc., Glen Burnie, Md., USA) according to the manufacturer's instructions to remove any genomic DNA contamination. Subsequently, $2 \mu \mathrm{g}$ of the DNase-treated total RNA was reverse transcribed to cDNA using a High-Capacity Reverse Transcription Kit (Applied Biosystems, Foster City, Calif., USA) and primed with random primers according to the manufacturer's instructions. Sequences for the genes of interest have been submitted to the GenBank.

All qPCRs were performed in duplicate using SYBRgreen ${ }^{\circledR}$ technology on the Bio-Rad iQ5 real-time platform (Bio-Rad Labo- ratories, Hercules, Calif., USA) using targeted primers made from the sequences from the libraries. Primers for targeted genes (table 1) were designed using Primer 3 v.0.4.0 (http://frodo.wi.mit. edu) from those sequences identified in the libraries. All primers were synthesized by Invitrogen ${ }^{\mathrm{TM}}$. All qPCR reactions $(12 \mu \mathrm{l}$ total volumes) were composed of: $6.0 \mu \mathrm{l} 2 \times$ master mix (Applied Biosystems), $360 \mathrm{nM}$ of each primer, $50 \mathrm{ng}$ cDNA template, and molecular grade water. For controls, the template was replaced with molecular-grade water or the no-reverse transcriptase control. PCR conditions were as follows: $94^{\circ} \mathrm{C}$ for $15 \mathrm{~s}, 56^{\circ} \mathrm{C}$ for $15 \mathrm{~s}$ and $72^{\circ} \mathrm{C}$ for $30 \mathrm{~s}$ for 40 amplification cycles.

Relative transcript abundances (i.e. number of transcripts for a gene of interest/total number of transcripts within the library) were compared between male and female libraries. All gene expression data were normalized: elongation factor 1-a (ef1a) was chosen based upon its low coefficient of variation. Expression levels of several commonly used reference genes, ef $1 a$, ribosomal protein S18 (rps18), ribosomal protein L22 (rpl22), and $\beta$-actin (actb), were compared between tissues. Expression of efla was found not to differ between tissues as well as having the lowest coefficient of variation $(\mathrm{CV}=0.04)$ of those potential reference genes analyzed in this study. Therefore, expressions of all genes of interest were normalized to ef1a using the $\Delta \Delta \mathrm{Ct}$ method. Gene-of-interest expression data are provided relative to mean testis expression except for $d m r t 1$, which is provided relative to females. All gene expression data were compared between tissues using a paired t test to test for group differences using SYSTAT 10.2 (Systat Software, San Jose, Calif., USA). Results from the qRT-PCR are expressed as mean fold change \pm standard error of the mean (SEM). 


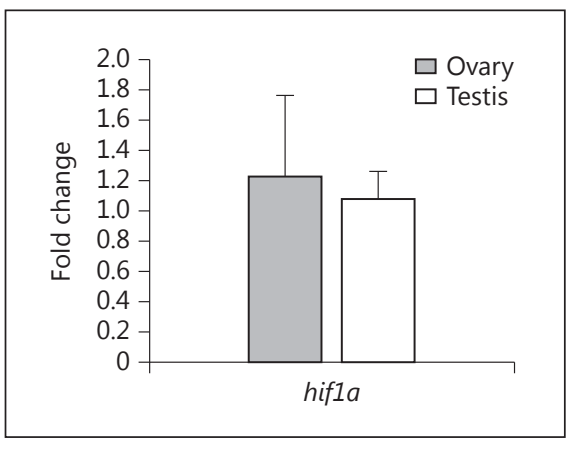

Fig. 1. Relative transcript abundance for a gene transcript not expected to be altered between the sexes, hypoxia-inducible factor 1-a (hif1a), was also quantified. Transcript abundance (mean \pm SEM) is relative to the mean abundance determined on testis samples. No significant difference $(\mathrm{p}<0.05)$ was found between the sexes using t test ( $n=6$ for each sex).

Table 2. Statistics of sequencing results of gonad tissues from shovelnose sturgeon generated by the GS-FLX platform

\begin{tabular}{lccc}
\hline & Testis & Ovary & Total \\
\hline Sequences in library & 12,238 & 36,089 & 48,327 \\
Isotigs & 496 & 2,907 & 3,403 \\
Singletons & 11,742 & 7,406 & 19,148 \\
Annotated & 1,095 & 10,313 & 11,408 \\
Mean e value & $1.01 \mathrm{e}^{-6}$ & $7.59 \mathrm{e}^{-7}$ & $7.83 \mathrm{e}^{-7}$ \\
\hline
\end{tabular}

\section{Results}

\section{Libraries}

The female library was much larger than the male library (table 2); it contained more than 117,000 reads comprising 36,089 sequences, while the male library only had 30,016 reads comprising 12,238 sequences. The percent of annotated sequences also differed between the libraries, with $28.6 \%$ in the female library and only $8.9 \%$ of the male library. Only 469 transcripts were common between libraries, while 5,244 sequences were unique to the female library, and 336 sequences were unique to the male library. Transcripts for genes known to play a role in sex differentiation, such as foxl2, sox9, vasa, and amh were not found in either library or found as a single sequence in both libraries. However, dmrt1 was detected in the testis library, but not in the ovary library. Genes associated with 'Wnt' and 'catenin' were found in both libraries but were much more abundant in the ovary library. A total of
88 transcripts associated with 'Wnt' were identified in the ovary library and only 2 in the testis library. In addition, 48 transcripts associated with 'catenin' were found in the ovary library, while only 1 transcript was linked with 'catenin' in the testis library. Therefore, we mined these transcripts to identify potentially significant transcripts in sex differentiation. Two genes known as antagonists to the Wnt cascade, dickkopf 1 ( $d k k 1)$ and dapperhomolog 1 (dact1), were present only in the ovary library. The sequences for all genes used to design transcript specific primers are currently available in GenBank (http://www. ncbi.nlm.nih.gov/).

\section{Quantitative Real-Time PCR}

Results from the qPCR showed that ef $1 a$ had the lowest coefficient of variation $(\mathrm{CV}=0.04)$ and was not found to differ between tissues $(p=0.11)$. A gene thought to be not affected by sex, hypoxia-inducible factor 1-a (hif1a), did not differ between the tissues $(\mathrm{p}=0.82)$ but was highly variable $(\mathrm{CV}=15.05$; fig. 1$)$. A significant difference in $d m r t 1$ transcript abundance between testes and ovaries $(\mathrm{p}=0.02$; fig. $2 \mathrm{~A})$ was observed. Upon further analysis, melt curve data suggests 2 potential products in ovaries, while mostly a single product was found in the testes (fig. 3). Although foxl2 transcripts were not identified from the NGS run, we nonetheless examined its expression using qPCR. Expression of foxl2 was 5.31-fold ( \pm $0.63)$ greater in females than in males ( $p=0.01$; fig. $2 \mathrm{~A})$. Both antagonists to the Wnt cascade, dact 1 and $d k k 1$, were highly upregulated in the ovary. Abundance of dact 1 was 207.53-fold ( \pm 43.58$)$ greater in ovary than in testis ( $p$ $<0.01)$, and $d k k 1$ transcripts were 1,819.13-fold ( \pm 183.41$)$ greater in ovary than in testis ( $\mathrm{p}<0.01$; fig. $2 \mathrm{~B}$ ).

\section{Discussion}

Our study goal was to identify sex-specific gene transcripts that could be used to determine sex in shovelnose sturgeon and potentially other sturgeon species. We identified several genes that had a sex-specific expression pattern but also propose a potential pathway for cell differentiation in gonads of shovelnose sturgeon. The use of transcript libraries generated by NGS was found to be a useful method for obtaining species-specific sequence information that can be used to develop qPCR assays to test future hypothesis.

Transcript libraries developed for this study were not of similar sizes. We found a greater number of transcripts in the ovary compared to the testis. This was not surpris- 
Fig. 2. Relative transcript abundance for A doublesex and mab-3-related transcription factor 1 (dmrt1) and forkhead box L2 (foxl2) and B 2 antagonists to the Wnt cascade, dickkopf 1 ( $d k k 1)$ and dapperhomo$\log 1$ (dact1). Transcript abundances are represented as means \pm SEM and relative to testis samples except for $d m r t 1$, which is relative to ovary samples. Asterisks above bars indicate significant difference $(\mathrm{p}<$ $0.05)$ between the sexes using t test $(n=6$ for each sex).

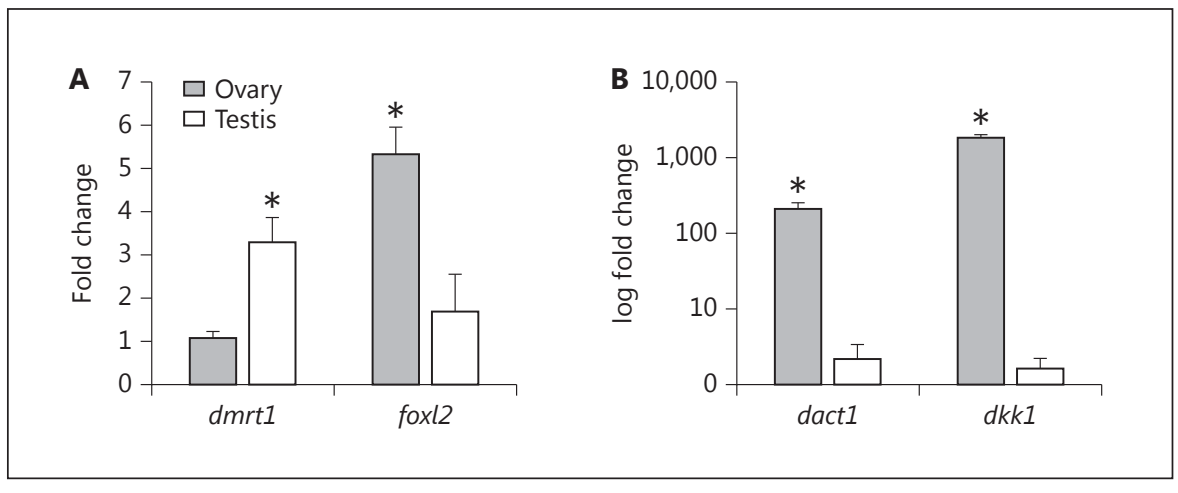

ing since maternally derived transcripts are deposited in developing eggs throughout oogenesis in teleosts [Lyman-Gingerich and Pelegri, 2007] and are likely stored for later use by the developing embryo. Thus, the greater number of sequences in the ovary library suggests a potential pool of maternal transcripts.

We mined the libraries to obtain sequences of genes known to regulate sex differentiation in other animals. Unfortunately, many of the sex-specific genes were not found in either library, while others were found as a partial single sequence in both libraries. We were successful in identifying some gene transcripts known to play a role in sex determination and differentiation. One gene that has been linked with sex differentiation, dmrt1, was only found in the testis library; this was confirmed using qPCR (fig. 2A), which is similar to what has been previously reported for Acipenser fulvescens [Hale et al., 2010]. This is contrary to what has been previously reported by our lab, where we found that $d m r t 1$ was expressed at about the same levels in male and female shovelnose sturgeon [Amberg et al., 2010]. Melt curve analysis in this study indicated $2 \mathrm{dmrt} 1$ products in ovaries and generally only 1 in testes. Different forms of $d m r t 1$ have been previously reported in fishes [Liu et al., 2007; Alam et al., 2008], and these variants have sex-specific expression patterns in Monopterus albus [Huang et al., 2005]. Unfortunately, the functions of these different forms of $d m r t 1$ remain unknown, although it is speculated that they play a role in the differentiation and development of sex tissues [Scholz et al., 2003; Huang et al., 2005; Liu et al., 2007]. If this is true, the potential forms of $d m r t 1$ in shovelnose sturgeon may have sex-specific functions and should be further studied.

The highly conserved transcription factor foxl2 was significantly upregulated in ovaries compared to that of testes. This gene has been found to be upregulated in ova-

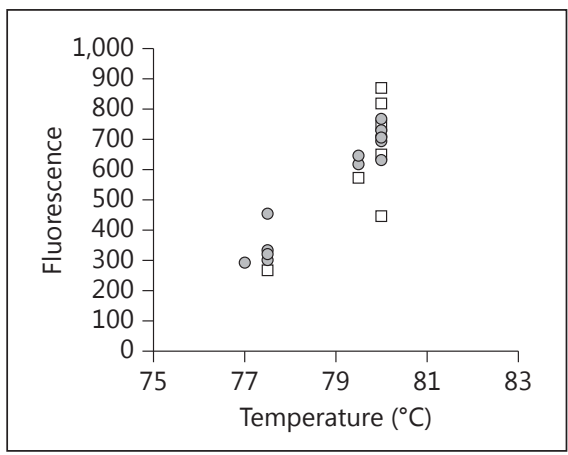

Fig. 3. Results from the melt curve analysis of $d m r t 1$ expression in shovelnose sturgeon gonads. White squares represent the level of fluorescence at a specific temperature for testes, and grey circles for ovaries.

ries from several other fishes [Liu et al., 2007; Alam et al., 2008; Ijiri et al., 2008; Vizziano-Cantonnet et al., 2008; $\mathrm{Wu}$ et al., 2008], including the shovelnose sturgeon [Liu et al., 2007; Alam et al., 2008; Ijiri et al., 2008; VizzianoCantonnet et al., 2008; Wu et al., 2008; Amberg et al., 2010]. It is typically thought that the transcription factor SRY, encoded by the Y chromosome, is responsible for testis differentiation, but this can still occur without SRY. By deleting Foxl2 in mice, testis-specific genes are upregulated [Uhlenhaut et al., 2009]. Taken together, this suggests that foxl2 may play a significant role in sex differentiation in fishes. However, the mechanism regulating the expression of foxl2 remains unknown.

Of particular interest were members of the Wnt family of developmental signaling molecules for their role in cell differentiation. This family has been linked in testicular development and suppression of developmental pathways in ovaries [Tevosian and Manuylov, 2008]. When $\mathrm{WNT}$ is present, it binds to frizzled-related protein which 
Fig. 4. Diagram of the Wnt cascade as potentially involved in sex determination/ differentiation in shovelnose sturgeon. In testes $(\mathbf{A})$, Wnt binds to the protein frizzled and activates the protein dishevelled. Dishevelled inhibits the axin/Gsk3/APC complex, and $\beta$-catenin is allowed to accumulate and then interact with Lef/Tcf in the nucleus, resulting in the expression of $\beta$-catenin/Lef/Tcf-responsive genes. In ovaries (B), proteins encoded by $d k k 1$ and dact 1 limit the binding of wnt and the activation of the protein dishevelled, respectively. This suppresses $\beta$-catenin/Lef/Tcfresponsive genes by promoting the degradation of $\beta$-catenin by the axin/Gsk3/APC complex.

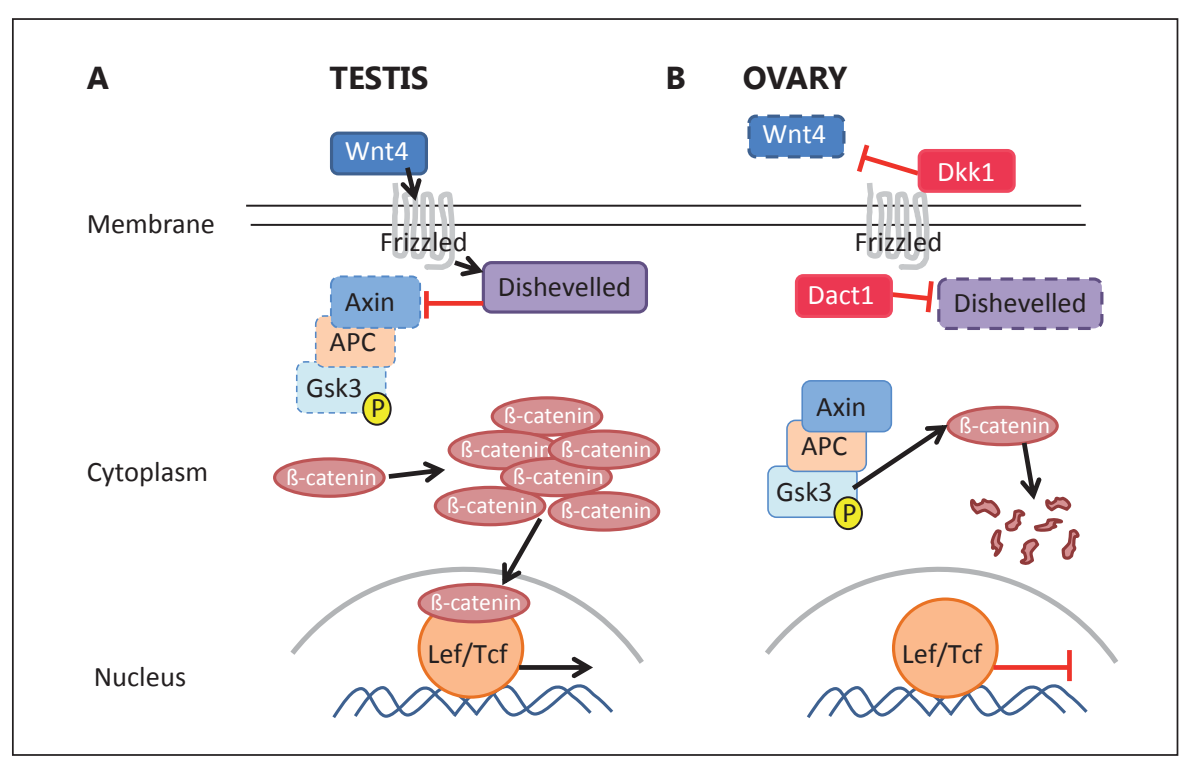

utilizes the protein dishevelled. This in turn inhibits the formation of the axin/Gsk3/APC complex and allows $\beta$-catenin to accumulate in the cell, to enter the nucleus and to form $\beta$-catenin/Lef/Tcf complexes, which are transcription factors that can control the fate of the cell. If the axin/Gsk3/APC complex is present, $\beta$-catenin is degraded and the interaction between $\beta$-catenin and Lef/Tcf in the nucleus is limited and decreases the expression of $\beta$-catenin/Lef/Tcf responsive genes. This cascade has been found to play a role in sex differentiation in animals [Tevosian and Manuylov, 2008] and may play a significant role in sex differentiation in sturgeons (see fig. 4 for a schematic representation of this cellular pathway).

Genes associated with 'Wnt' and 'catenin' were found in both libraries but were much more abundant in the ovary library. Furthermore, 2 genes known as antagonists to the Wnt cascade, $d k k 1$ and dact1, were only present in the ovary library. DKK1 inhibits the binding of WNT to frizzled complex in the cell membrane, thus blocking the activation of the protein dishevelled, whereas DACT1 promotes the degradation of the protein dishevelled (fig. 4). As such, both DKK1 and DACT1 enable the axin/ Gsk3/APC complex to degrade $\beta$-catenin and minimize the expression of $\beta$-catenin/LEF/TCF-responsive genes, resulting in a different cell type than those lacking either DKK1 or DACT1. DKK1 has been found to play a role in normal development of testis in mice [Manuylov et al., 2008; Combes et al., 2011]. But unlike mice, we found that $d k k 1$ was upregulated in ovaries rather than testes. This difference in expression could be explained by specific functions of this gene in different species or perhaps due to differences in expression depending on gonadal stage. Mice studies have focused on germ cell differentiation, while our study was conducted with differentiated gonads. Further investigations in the developmental expression patterns of $d k k 1$ in sturgeon need to be conducted since it is an extracellular protein that binds to the protein frizzled and circulates in the blood. If elevated in sexually immature females, Dkk1 may be a reliable noninvasive method of gender identification in sturgeon. Unlike $d k k 1$, dact 1 has not been linked with sex differentiation, but appears to play a role in cell development [Arguello and Cheyette, 2010; Okerlund et al., 2010]. The high expression of these genes in our study suggests that it may play a role in ovarian development.

An alternative explanation for the observed upregulation of $d k k 1$ and dact 1 in ovaries of shovelnose sturgeon could be related to their role in oocyte maintenance, particularly as it relates to folliculogenesis and oogenesis. Recently, wnt 11 and $w n t 9 b$ were found highly expressed in granulosa cells and oocytes of rainbow trout (Oncorhynchus mykiss) suggesting their involvement in folliculogenesis and oogenesis in teleosts [Nicol and Guiguen, 2011]. Regardless, expression patterns of $d k k 1$ may be an extremely valuable biomarker as a noninvasive method for gender identification in sturgeon.

Sox (Sry-related HMG box) genes were found in transcript libraries and included sox2, sox3, sox 11, and sox $11 a$. These genes are a family of transcription factors known to be involved in sex determination in several mammals 
and teleost fishes. In particular, sox9 has been associated with testicular development, with sox9-expressing cells directly surrounding germ cells which then differentiate into Sertoli cells. However, during early gonadal differentiation, an incomplete sexually dimorphic pattern has been described for sox 9 in several fish species, with expression also being reported in females [Vizziano et al., 2007; Nakamura et al., 2008]. These results suggest that sox 9 does not play a major role in early sex determination and differentiation [Nakamoto et al., 2005]. Up to 8 sox genes (sox2, sox3, sox4, sox9, sox11, sox17, sox19, and sox21) have been reported from the genomes of both the European Atlantic sturgeon (A. sturio) [Hett and Ludwig, 2005; Hett et al., 2005] and the lake sturgeon [McCormick et al., 2008]. Similar to what has been reported for other teleosts, sox genes are likely involved in sex determination in sturgeon species, but are probably not the primary signal controlling sex in this group of fish.

In summary, we used NGS to identify potentially important sex-specific genes in shovelnose sturgeon. Four genes, $d m r t 1$, foxl2, $d k k 1$, and dact1, the latter 2 known to be antagonists to the Wnt cascade, were found to be highly upregulated in ovarian tissues of shovelnose sturgeon. This is the first study that has identified $d k k 1$ and dact 1 and their potential importance in sex differentiation in sturgeon species which needs to be further researched. We speculate that the use of circulating Dkk1 may be a viable female-specific marker for sturgeon, but much more research is needed to describe the expression patterns during gonadal development and to better understand the role of these genes in sex determination and differentiation.

\section{Acknowledgements}

Special thanks to Tom Stefanavage of the Indiana Department of Natural Resources and the Indiana Animal Disease Diagnostic Laboratory at Purdue University for donating the fishes. We would also like to thank the many graduate and undergraduate students who helped to collect the fishes from the Wabash River and then processed tissues. Thanks also to Jessica Leet and Jennifer Meyer for all of their help in the analyses of samples.

\section{References}

-Alam MA, Kobayashi Y, Horiguchi R, Hirai T, Nakamura M: Molecular cloning and quantitative expression of sexually dimorphic markers Dmrt1 and Foxl2 during female-to-male sex change in Epinephelus merra. Gen Comp Endocrinol 157:75-85 (2008).

- Alfaqih MA, Steele CA, Morris RT, Thorgaard $\mathrm{GH}$ : Comparative genome mapping reveals evidence of gene conversion between Sox9 paralogs of rainbow trout (Oncorhynchus mykiss). Comp Biochem Physiol Part D:Genomics Proteomics 4:147-153 (2009).

-Amberg JJ, Goforth R, Stefanavage T, Sepúlveda MS: Sexually dimorphic gene expression in the gonad and liver of shovelnose sturgeon (Scaphirhynchus platorynchus). Fish Physiol Biochem 36:923-932 (2010).

Arguello A, Cheyette BNR: Role of Dact1 in cortical interneuron morphology and synapse development (abstract). Soc Neurosci 40 (2010).

Combes AN, Bowles J, Feng CW, Chiu HS, Khoo PL, et al: Expression and functional analysis of $d k k 1$ during early gonadal development. Sex Dev 5:124-130 (2011).

Devlin RH, Nagahama Y: Sex determination and sex differentiation in fish: an overview of genetic, physiological, and environmental influences. Aquaculture 208:191-364 (2002).

- Hale MC, McCormick CR, Jackson JR, DeWoody JA: Next-generation pyrosequencing of gonad transcriptomes in the polyploid lake sturgeon (Acipenser fulvescens): the relative mer- its of normalization and rarefaction in gene discovery. BMC Genomics 10:203 (2009).

Hale MC, Jackson JR, DeWoody JA: Discovery and evaluation of candidate sex-determining genes and xenobiotics in the gonads of lake sturgeon (Acipenser fulvescens). Genetica 138: 745-756 (2010).

Harshbarger JC, Coffey MJ, Young MY: Intersexes in Mississippi River shovelnose sturgeon sampled below Saint Louis, Missouri, USA. Mar Environ Res 50:247-250 (2000).

-Hett AK, Ludwig A: SRY-related (Sox) genes in the genome of European Atlantic sturgeon (Acipenser sturio). Genome 48:181-186 (2005).

Hett AK, Pitra C, Jenneckens I, Ludwig A: Characterization of Sox9 in European Atlantic sturgeon (Acipenser sturio). J Hered 96:150154 (2005)

Huang X, Guo YQ, Shui Y, Gao S, Yu HS, et al: Multiple alternative splicing and differential expression of $d m r t 1$ during gonad transformation of the rice field eel. Biol Reprod 73: 1017-1024 (2005)

-Ijiri S, Kaneko H, Kobayashi T, Wang D-S, Sakai $F$, et al: Sexual dimorphic expression of genes in gonads during early differentiation of a teleost fish, the Nile tilapia Oreochromis niloticus. Biol Reprod 78:333-341 (2008).

Keyvanshokooh S, Gharaei A: A review of sex determination and searches for sex-specific markers in sturgeon. Aquac Res 41:e1-e7 (2010).
Kumar S, Blaxter ML: Comparing de novo assemblers for 454 transcriptome data. BMC Genomics 11:571 (2010)

Liu ZH, Wu FR, Jiao BW, Zhang XY, Hu CJ, et al: Molecular cloning of doublesex and mab-3-related transcription factor 1 , forkhead transcription factor gene 2 , and two types of cytochrome P450 aromatase in Southern catfish and their possible roles in sex differentiation. J Endocrinol 194:223241 (2007)

Lyman-Gingerich J, Pelegri F: Maternal factors in fish oogenesis and embryonic development, in Babin PJ, Cerdà J, Lubzens E (eds): The Fish Oocyte: From Basic Studies to Biotechnological Applications, pp 141-174 (Springer, Dordrecht 2007).

- Manuylov NL, Smagulova FO, Leach L, Tevosian SG: Ovarian development in mice requires the GATA4-FOG2 transcription complex. Development 135:3731-3743 (2008).

McCormick CR, Bos DH, DeWoody JA: Multiple molecular approaches yield no evidence for sex-determining genes in lake sturgeon (Acipenser fulvescens). J Appl Ichthyol 24: 643-645 (2008).

Nakamoto M, Suzuki A, Matsuda M, Nagahama Y, Shibata N: Testicular type Sox9 is not involved in sex determination but might be in the development of testicular structures in the medaka, Oryzias latipes. Biochem Biophys Res Commun 333:729-736 (2005). 
Nakamura S, Aoki Y, Saito D, Kuroki Y, Fujiyama A, et al: Sox9b/sox9a2-EGFP transgenic medaka reveals the morphological reorganization of the gonads and a common precursor of both the female and male supporting cells. Mol Reprod Dev 75:472-476 (2008).

Nicol B, Guiguen, Y: Expression profiling of Wnt signaling genes during gonadal differentiation and gametogenesis in rainbow trout. Sex Dev 5:318-329 (2011).

Okerlund ND, Kivimäe S, Tong CK, Peng IF, Ullian EM, Cheyette BNR: Dact1 is a postsynaptic protein required for dendrite, spine, and excitatory synapse development in the mouse forebrain. J Neurosci 30:4362-4368 (2010).

- Schirmer K, Fischer BB, Madureira DJ, Pillai S: Transcriptomics in ecotoxicology. Anal Bioanal Chem 397:917-923 (2010).
Scholz S, Rösler S, Schäffer M, Hornung U, Schartl $\mathrm{M}$, Gutzeit HO: Hormonal induction and stability of monosex populations in the medaka (Oryzias latipes): expression of sex-specific marker genes. Biol Reprod 69:673-678 (2003).

Siegfried KR: In search of determinants: gene expression during gonadal sex differentiation. J Fish Biol 76:1879-1902 (2010).

- Tevosian SG, Manuylov NL: To beta or not to beta: canonical beta-catenin signaling pathway and ovarian development. Dev Dyn 237: 3672-3680 (2008).

Uhlenhaut NH, Jakob S, Anlag K, Eisenberger T, Sekido R, et al: Somatic sex reprogramming of adult ovaries to testes by FOXL2 ablation. Cell 139:1130-1142 (2009).

Vizziano D, Randuineau G, Baron D, Cauty C, Guiguen Y: Characterization of early molecular sex differentiation in rainbow trout, Oncorhynchus mykiss. Dev Dyn 236:2198-2206 (2007).
Vizziano-Cantonnet D, Baron D, Mahè S, Cauty C, Fostier A, Guiguen Y: Estrogen treatment upregulates female genes but does not suppress all early testicular markers during rainbow trout male-to-female gonadal transdifferentiation. J Mol Endocrinol 41:277-288 (2008).

Wei Q, He J, Yang D, Zheng W, Li L: Status of sturgeon aquaculture and sturgeon trade in China: a review based on two recent nationwide surveys. J Appl Ichthyol 20:321-332 (2004).

Wu G-C, Tomy S, Nakamura M, Chang C-F: Dual roles of cyp19a1a in gonadal sex differentiation and development in the protandrous black porgy, Acanthopagrus schlegeli. Biol Reprod 79:1111-1120 (2008).

-Yarmohammadi M, Pourkazemi M, Chakmehdouz F, Kazemi R: Comparative study of male and female gonads in Persian sturgeon (Acipenser persicus) employing DNA-AFLP and CDNA-AFLP analysis. J Appl Ichthyol 27:510-513 (2011) 